\title{
Myocarditis in a dog with leishmaniasis and dirofilariasis coinfection
}

\begin{abstract}
Heartworm disease and leishmaniasis are parasitic diseases caused by the nematode Dirofilaria immitis and by the protozoan Leishmania infantum respectively. These two vector-borne parasitoses share not only the same geographic distribution as coincident foci of endemicity. Brazil is considered an endemic country for these two parasitoses. Cardiac symptomatology is well defined in heartworm disease, whereas leishmaniasis is still not well defined. Some cardiac biomarkers are important to clarify cardiac damage; among them we have the enzyme Creatinine kinase (CK), its CK-MB isoenzyme, asparato-transaminase (AST) and lactate dehydrogenase (LDH). The electrocardiogram examination is also important as a marker of cardiac injury. In this sense, the study aimed to report a case of co-infection between these two parasitosis in a 5-year-old dog from the Center of Zoonoses of Fortaleza-Ceará.
\end{abstract}

Keywords: dirofilaria immitis, co-infection, Leishmania infantum
Volume 7 Issue 4 - 2018

\author{
Pedro Ernesto de Araújo Cunha,' Ana \\ Carolina Valente Cavalcante,' Paula Priscila \\ Correia Costa, ${ }^{1,2}$ \\ 'Department of Veterinary Science, State University of Ceara, \\ Brazil \\ ${ }^{2}$ Department of Pharmacology, Federal University of Ceara, \\ Brazil
}

Correspondence: Paula Priscila Correia Costa, Paula Priscila Correia Costa, College of Veterinary Medicine, State University of Ceara, College of Medicine, Federal University of Ceara, Fortaleza, Brazil, Tel +55(85) 996569812,

Email paula.priscila@uece.br

Received: May 04, 2018 | Published: August 13, 2018

\section{Case report}

Cardiovascular injury caused by visceral leishmaniasis was investigated at the Center of Zoonosis Control, Fortaleza (CCZ). CCZ is a public health agency responsible for the euthanasia of animals suffering from according to Brazilian legislation. This study was approved by the Institutional Ethical Committee, State University, Ceara (Protocol number 2891954/2016). Dogs that tested positive for Leishmaniasis on both immunochromatographic rapid test $(D P P \mathbb{}$ kit) and ELISA test (EIE-leishmaniose-canina-Bio-Manguinhos, EIE$L C$ kit), underwent blood collection for biochemistry test and ECG (ECGDeltaVet $(\mathrm{R})$ to evaluate possible heart damage before mandatory euthanasia. Unexpectedly, one of the studied animals displayed Dirofilaria immitis co-infection, ${ }^{1}$ which is not a common condition. This is a case study of a 5-years-old male Pit Bull dog that presented Leishmaniasis and Heartworm disease concomitantly. ${ }^{2}$ On physical examination, the dog presented weight loss, lesion on the tip of the ear and exfoliative dermatitis. Biochemistry tests and ECG showed the following results: creatine kinase $(C K) 138.1 \mathrm{U} / \mathrm{L}$; creatine kinase-MB $(C K-M B) 66 \mathrm{U} / \mathrm{L}$; aspartate transaminase $(A S T) 30 \mathrm{U} / \mathrm{dL}$; lactate dehydrogenase $(L D H) 366 \mathrm{U} / \mathrm{L}$; P wave 52ms; QRS complex 76ms; PR interval 120ms; QT interval 200ms; ST segment $148 \mathrm{~ms}$; QT interval $519.875 \mathrm{~ms}^{3}{ }^{3}$ Additionally, necropsy revealed large amount of long white/cream filarial worms in the heart identified as Dirofilaria immitis. Heartworms mainly occur in the right ventricle and pulmonary artery (Figure 1)

Leishmania infantum is the main causative agent for visceral leishmaniasis in Brazil, where it is considered as an endemic disease. $D$. immitis and L. infantum share not only the same geographic distribution but also endemic foci. Over recent decades, many authors have demonstrated heart injury related to Visceral Leishmaniasis in humans and dogs. ${ }^{4,5}$ Based on biochemistry analysis of the blood (except AST) and ECG, which indicated left atrioventricular overload, increased ventricular electrical activity and myocardial hypoxia and/or hydroelectrolytic imbalances, we confirm the diagnosis of myocarditis, possibly due to coinfection of $L$. infantum and D. immitis.

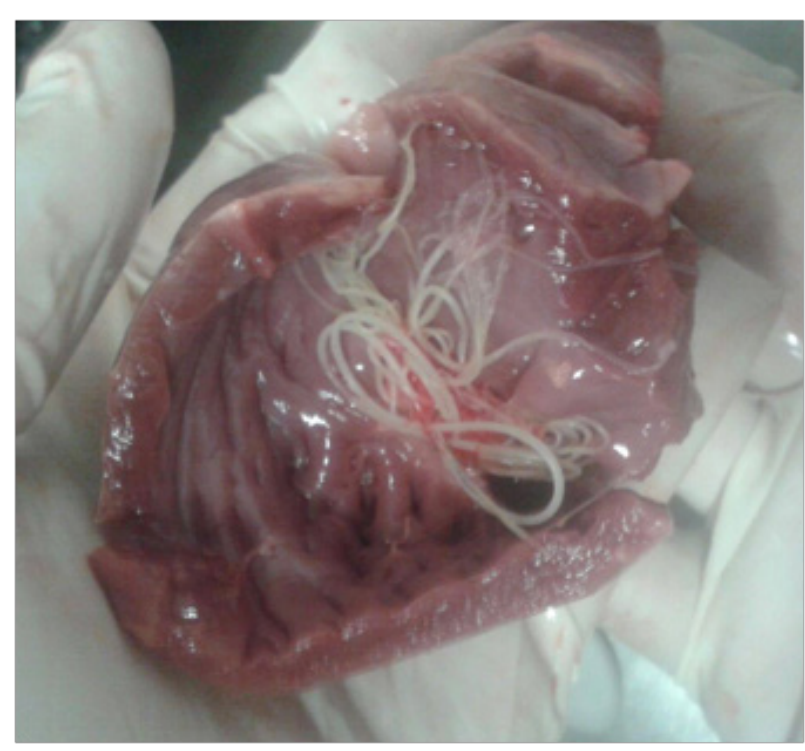

Figure I D. immitis inside the heart of the dog.

\section{Conclusion}

Heartworm disease and leishmaniasis are parasitic diseases caused by the nematode Dirofilaria immitis and by the protozoan Leishmania infantum respectively. These two vector-borne parasitoses share not only the same geographic distribution as coincident foci of endemicity. In this case, a dog co-infected with both parasites was reported. Therefore, it is very important to actively combat the responsible vectors, since the diseases mentioned above are zoonoses.

\section{Acknowledgements}

None. 


\section{Conflicts of interest}

Author declares there is no conflict of interest.

\section{References}

1. Magnis J, Lorentz S, Guardone L, et al. Morphometric analyses of canine blood microfilariae isolated by the Knott's test enable Dirofilaria and Acanthocheilonema (syn. Dipetalonema) immitis and D. repensspeciesspecific genus-specific diagnosis. Parasit Vectors. 2013;6:48.

2. Fernández-Cotrina J, Iniesta V, Belinchón-Lorenzo S, et al. Experimental model for reproduction of canine visceral leishmaniasis by Leishmania infantum. Vet Parasitol. 2013;192(1-3):118-128.
3. Silva RS, Langoni, H. Dirofilariose: Zoonose emergente negligenciada. Ciência Rural. 2009;39(5):1614-1623.

4. Puerto-alonso JL, Molina-ruano FJ, Gómez-soto F, et al. Leishmaniasis visceral con afectación cardíaca en un paciente inmunocompetente. Medicina Clínica. 2006;127(13):519.

5. López-Peña M, Alemañ N, Muñoz F, et al. Visceral leishmaniasis with cardiac involvement in a dog: a case report. Acta Vet Scand. 2009;51:20. 